\title{
An empirical study on effective factors on entrepreneurial orientation in Iranian banking industry
}

\author{
Hasan Darvish $^{\mathrm{a}}$, Seid Mahdy Alvani ${ }^{\mathrm{a}}$, Jamshid salehi sadagiani ${ }^{\mathrm{b}}$ and Hasan Abbaszadeh ${ }^{\mathrm{a}^{*}}$
}

${ }^{a}$ Department of Management, public administration, Payame Noor University, Tehran, Iran ${ }^{b}$ Department of Accounting \& Management of Allameh Tabatabai University, Tehran, Iran

\begin{tabular}{l}
\hline A R T I C L E I N F O \\
\hline Article history: \\
Received April 25, 2012 \\
Received in Revised form \\
June, 16, 2012 \\
Accepted 28 June 2012 \\
Available online \\
July 8 2012 \\
\hline Keywords: \\
Entrepreneurial orientation \\
Organizational and environmental \\
factors \\
Banking system
\end{tabular}

\section{A B S T R A C T}

During the past few years, many banks try to move from traditional banking system to entrepreneurial one to create new opportunities as well as changing the conditions to deal with the environmental threats. Therefore, recognizing the entrepreneurial orientation and the factors influencing plays an important role for amplifying the innovation and preparing the conditions for the banks to enter the risking process of entrepreneurship. The purpose of this article is to propose a model for entrepreneurial orientation, which can be used by policymakers and managers of banking system towards improving the entrepreneurial orientation. This paper performs a survey among 700 employees of private banks in Tehran, Iran. To collect the required data, the questionnaire was distributed randomly among 350 staffs of these banks and 184 were found to be useful to process. The results show that the entrepreneurial orientation, cultural factors and among organizations factors, making proper connections between organizational unit and high manager support had a good condition. Moreover, organizational conflicts, inappropriate rewarding system, economical and political conditions and the values were not considered as positive adjustment. Thus, the proposed model, as an aborigine pattern, can be used by policy makers and high managers of Iran's banking system to provide the necessary conditions to enter the entrepreneurial process in the banking system.

(c) 2012 Growing Science Ltd. All rights reserved.

\section{Introduction}

Banking system has faced some outstanding evolutions since 1990; the rate of these changes in recent years has accelerated due to the development of communication in facilities, globalization, deregulation, technology improvement, more specifically information technology (Kuratko \& Hodgetts, 2006). Nevertheless, the banking services in Iran is neither well diversified nor maintains the necessary quality and speed in equipping the resources and servicing the customers (Zahra \& Dess; Lumpkin \& Dess, 2006). In order to deal with problems and challenges of banking system, preparing the prerequisites of increasing the entrepreneurial orientation can be considered as an effective pattern for reaching the innovative goals, enhancing imitativeness as well as offering new

* Corresponding author. Tel: +9877555194

E-mail addresses: abaszadeh907@yahoo.com (H. Abaszadeh) 
products and business processes and subsequently improvement of servicing quality (Milles \& Covin, 2002). The investigations show that organizational, economical, cultural and political factors play important roles in entrepreneurship of banks in which arranging the appropriate economical, cultural and political conditions seems vital (Hodgetts, 2006). In other words, environmental factors can adjust the effects of organizational factors on entrepreneurial orientation of organizations (Hitt et al., 2007). The main question of this paper is to recognize the main components of entrepreneurial orientation and to formulate an appropriate model for it in banking system of Iran in which the main concern of the researchers is to recognize important factors and the contexts influencing entrepreneurial orientation. Hence, the main question is to determine the main factors influencing entrepreneurial orientation. Reviewing the literature shows that the experts have enumerated various factors in which in this research project by examining and categorizing them, a final model for factors impacting the entrepreneurial orientation in banking system will be determined. Therefore, the components and variables influencing the entrepreneurial orientation were recognized and described and then a conceptual model based on these variables and the linkage among them were proposed, subsequently the model was tested for being sound for the banking system of Iran. The results will empower the banking system managers to arrange the prerequisites for improving the entrepreneurial orientation.

\section{Literature review of entrepreneurial orientation}

One of the main approaches connecting entrepreneurial process for organization strategies is the entrepreneurial orientation (Covin \& Slevin, 1991). According to this approach, every organization's entrepreneurship status can be shown on a spectrum from passive or conservative to aggressive or entrepreneurial (Lumpkin \& Dess, 2001). As long as the organization is active, its managers consider innovation, imitativeness, leadership and risk and highlight the importance of recognizing, evaluating and exploiting the opportunities compared with passive ones (Knight, 2000). Miller (1983) believes that organizations with entrepreneurial orientation are more innovative in market and product and shows more imitativeness and risk in their decision. These features in turn help them gain a strategic position in their competitive environment (Miller \& Friesen, 1982). According to Covin and Slevin (1991) entrepreneurial orientation refers to strategic situation of an organization which is innovative, initiative and has the tendency to risk (Covin \& Miles, 1999; Patrick, M., \& Davis, 2010). Innovation is also considered as solving the problems whenever the new informative and communicative technologies as well as modern systems are utilized in the organization's management. Moreover, innovation is the orientation of organizations in research and development, supporting new ideas, which are separated from the previously determined ones (Morris, 1998). Being initiative; refers to forecast the needs, opportunities and future environmental changes as well as utilizing new approaches and techniques for meeting and using them. Risk is another tendency to invest in the projects (Lee \& Peterson, 2000), which results in high profits and outcomes but can lead to great defeats as well. The tendency to risk is considered as the prerequisite of success in the global competition (Covin et al., 2006). In this research project, the following actions were conducted after the primary studies and reviewing the related literature and the current models of organizational entrepreneurship:

- The reliable related models were extracted from the literature and various dimensions, components and variables were scrutinized.

- The model of prerequisites and the influencing factors on entrepreneurship suggested by Jaworski and Kohli (1993) were considered as the independent variables influencing the entrepreneurship and the dimensions of Covin and Slevin (1999) were regarded as the dependent variable in the conceptual model.

- Moreover, the condition of the society in general and that of banking system were regarded as adjusting variable of the conceptual model. 
- Some other models of personal, environmental and organizational factors influencing the entrepreneurship were utilized for formulating the conceptual model of this research. Therefore, the following model was proposed:

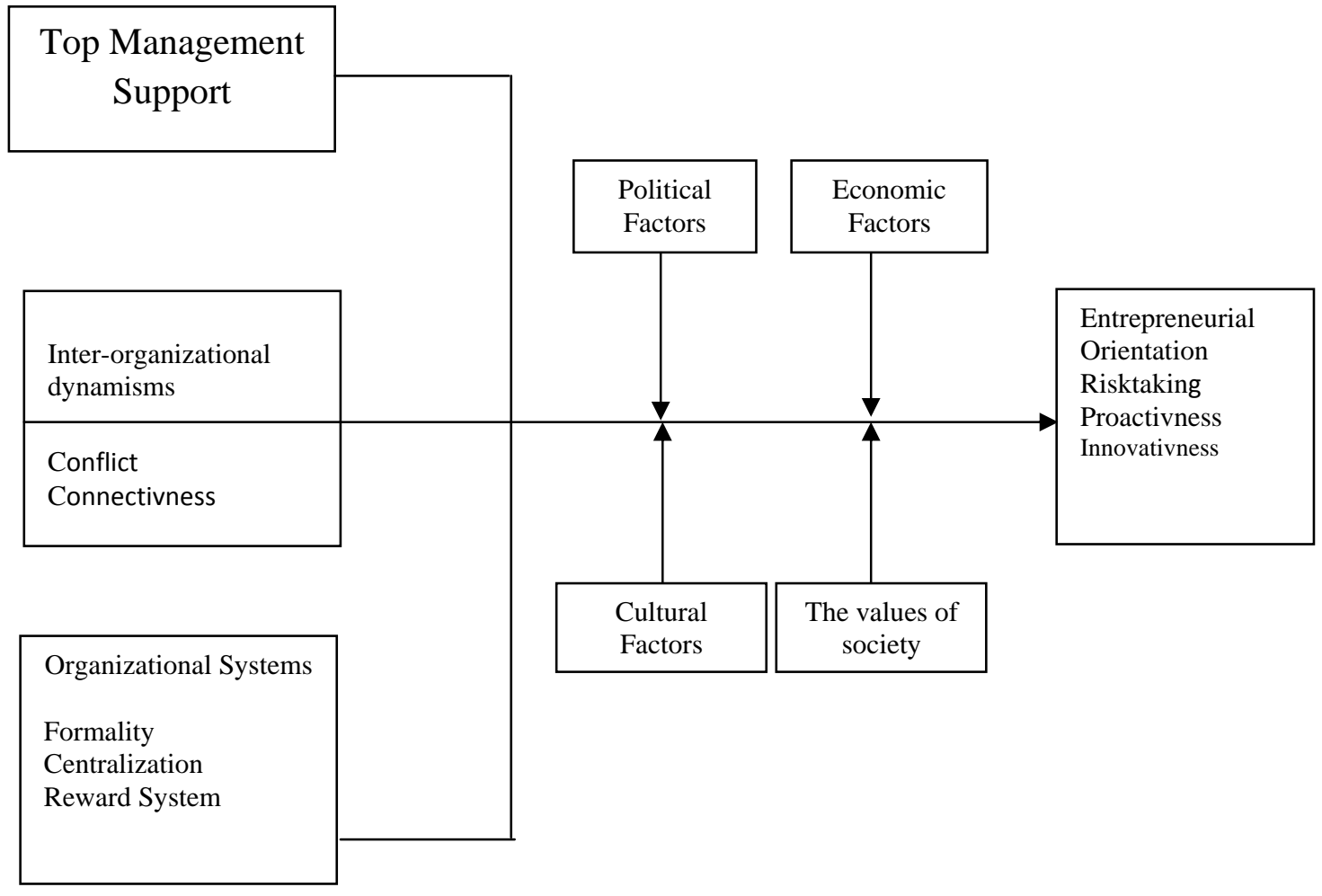

Fig. 1. Conceptual model of research

\section{Literature background}

Holt (2003) considered the role of factors influencing the entrepreneurial orientation and its outcomes by conducting a research project with the title of factors and the results of organizational entrepreneurial in air force of USA. Based on the previous researches by various experts, different organizational factors influencing the entrepreneurial orientation were divided into the following categories of: appropriate use of rewarding system, senior manager support, availability of resources, supporting organizational structure and the tendency to risk (Holt, 2007). In another research with the title of "entrepreneurial actions of organization manager" Hornsby et al. (2009) considered the role of various managers of the organization in implementing organizational entrepreneurial strategy. The result of their research showed that managers of different levels have different duties in shaping a structure for implementing the entrepreneurial ideas and as a comparison, senior managers have higher organizational power for implementing the entrepreneurial ideas to operational managers. Moreover, the findings showed that there was a significance relationship between senior manager's supports, freedom of task and the number of implemented ideas. The higher managers are more competent in attracting the support of senior managers and have higher freedom of task comparing to the other managers as well. With reference to the findings of this research, freedom of task empower the senior and middle managers to be implement the entrepreneurial ideas more successfully, whereas in operational management level, this kind of freedom doesn't influence the entrepreneurial orientation (Hornsby et al., 2009).

\section{Hypotheses}

The hypotheses were formulated based on the conceptual model of this research, extracted from the scientific resources and the conditions of the society. Therefore, the hypotheses are to be explained here after expressing the conceptual model. 


\subsection{Main hypotheses}

1. Organizational factors influence the entrepreneurial orientation of banking system.

2. Environmental factors significantly modify the extent of organizational factors' influence on entrepreneurial orientation in banking system of Iran.

3. The condition of entrepreneurial orientation in banking system of Iran is considered to be sound.

\subsubsection{Sub-hypotheses of 1st main hypothesis}

1. Senior managers' actions influence the entrepreneurial orientation in banking system of Iran.

2. Inter-organizational dynamisms influence the entrepreneurial orientation in banking system of Iran.

3. Organizational systems influence the entrepreneurial orientation in banking system of Iran.

\subsubsection{Sub-hypotheses of 2nd main hypothesis}

1. Cultural factors significantly modify the relationship between organizational factors and the entrepreneurial orientation in banking system of Iran.

2. Economic factors significantly modify the relationship between organizational factors and the entrepreneurial orientation in banking system of Iran.

3. Political factors significantly modify the relationship between organizational factors and the entrepreneurial orientation in banking system of Iran.

4. The values of society significantly modify the relationship between organizational factors and the entrepreneurial orientation in banking system of Iran.

\section{Methodology and Procedure}

This research project is practical on the basis of its purpose and regarding the techniques of collecting the required data is analytical descriptive, the method of analyzing the collected data is correlation as well. The literature background of this research was collected by use of desk studies, databases and interviewing with experts. Therefore, based on the organizational factors of Hornssby et al. (2009) as well as entrepreneurial orientation of Covin and Slevin (1991), theoretical framework of this research project was determined. The society of this research project includes 1200 employees of private banks in Tehran. In order to collect the required data, the questionnaire was distributed randomly among 350 employees and 284 of them were returned and used for data analysis. The questions of the questionnaire were about different components of entrepreneurial orientation, organizational and environmental factors as well as their effects on entrepreneurial orientation in banking system of Iran in which for each component, 3 questions were designed (total number of 35 questions). Then, 30 questionnaires were gathered as a pre -test and by use of SPSS, its reliability was determined to be 87.6 which means the above mentioned questionnaire was reliable. In order to analyze the data, descriptive techniques and statistical analysis, more specially correlation, were utilized. As the hypotheses test required correlation analysis, and the variables were qualitative, Spearman correlation coefficient was used. In order to design the questionnaire, five options Likert scale was utilized.

Moreover, in order to analyze the internal structure of the questionnaire and determining the factors composing each latent variable, factor analysis was used. In this section, by use of the above mentioned factor analysis, the equations of each latent variable are to be extracted and interpreted. With reference to the results, all of loading factors of each organizational factors including supreme management, inter-organization dynamisms and organizational systems and environmental factors including economic, political, cultural and society's values are meaningful in 99 percent confidence level. All of factor loadings of variables such as innovation, initiative and risk, which were associated with entrepreneurial orientation were considered meaningful at confidence level of 99 percent. The final indexes ( $p$-value=1.0000, RMSEA=0.000) showed goodness of fit index for the suggested 
model. It means that all of the dimensions, components and variables defined for entrepreneurial orientation, organizational and environmental factors were appropriate and can determine the above mentioned variables experimentally.

\subsection{Evaluation of the proposed model}

As it was mentioned previously, regarding the theoretical framework of the research, the conceptual model (Fig. 1) is considered for organizational and entrepreneurial orientation. In order to find a more appropriate model for banking systems, discovering factor analysis was used in which some variables were merged and ultimately the final conceptual model was determined. To support this model, LISREL software was used. In this section, in order to calculate and evaluate the fit of this model, independent variable, organizational factors, modifying variable, environmental variables, and dependent variable, entrepreneurial orientation, are discussed.

\subsubsection{Fitness of structural section of conceptual model}

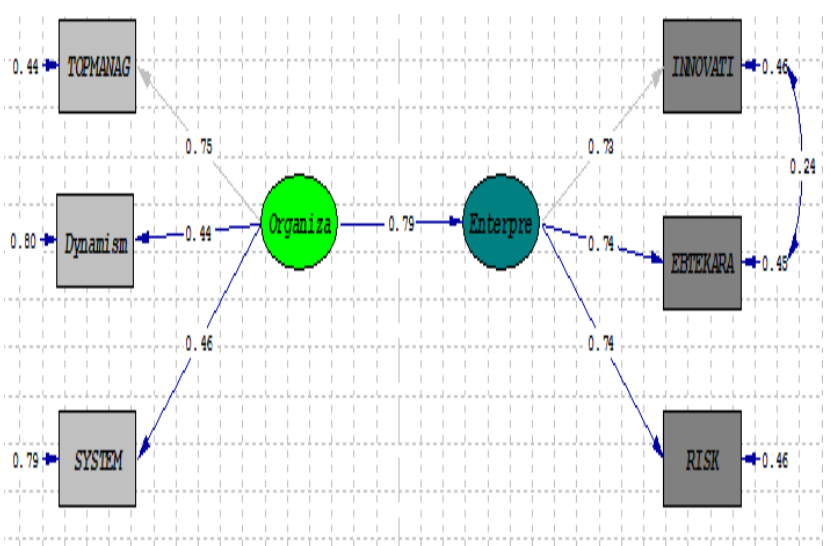

Chi-Square $=15,43, \mathrm{df}=7, \mathrm{p}$-value $=0.03084, \mathrm{RMSEA}=0.065$

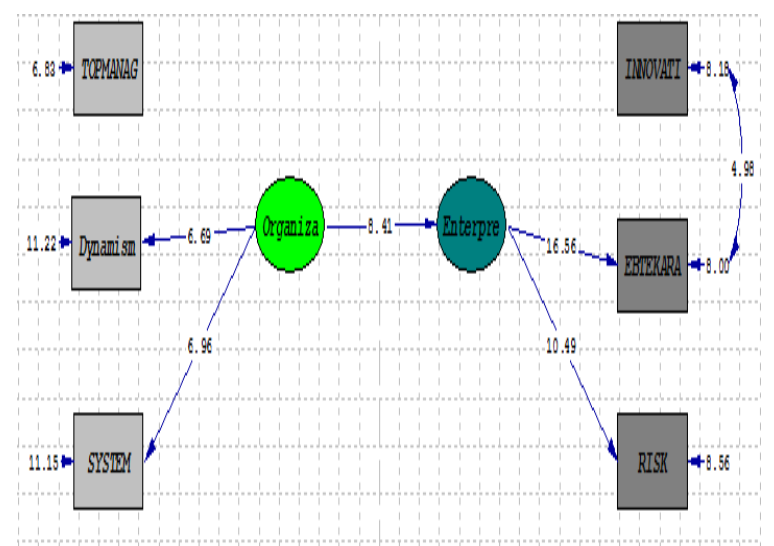

Chi-Square $=15,43, \mathrm{df}=7, \mathrm{p}$-value $=0.03084, \mathrm{RMSEA}=0.065$

$$
\mathrm{GFI}=0.98, \mathrm{RMSEA}=0.065, \mathrm{CFI}=0.99, \mathrm{AGFI}=0.95, \mathrm{NFI}=0.98, \mathrm{NNFI}=0.97
$$

Fig. 1. The results Fitness of the model without considering the modifying variables
Fig. 2. t-student values for Fitness of the model without considering the modifying variables

Since the fitness indexes are higher than the determined ones, we can conclude that the conceptual model has a sound fitness; it means that the collected data shows the relations of the conceptual model. All of factor loadings are meaningful at confidence level of 99 percent.

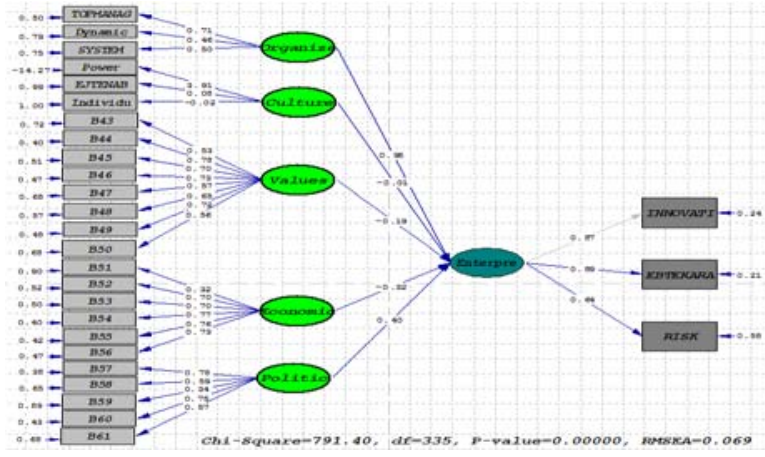

Fig. 3. Fitness of conceptual model in the presence of modifying variables

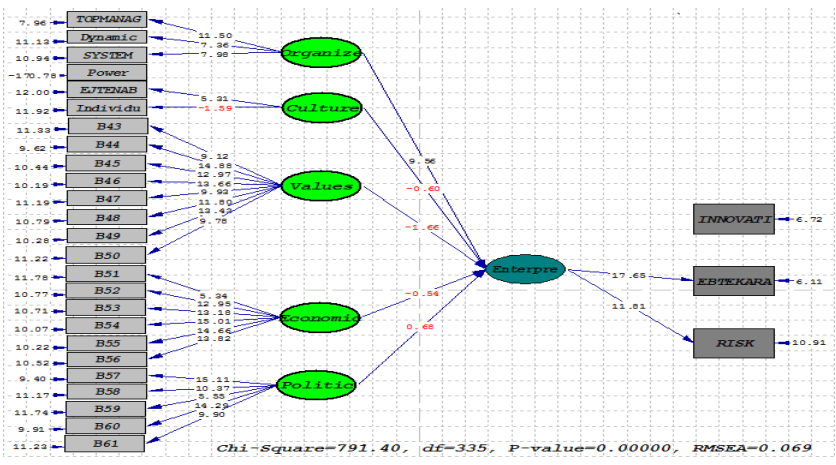

Fig. 4. T-student values for fitness of conceptual model in the presence of modifying variables

Organizational factors have a significance effect on entrepreneurial orientation and in general independent variable of organizational factor $\left(R^{2}=0.67\right)$, determines $67 \%$ of changes of independent 
variable of entrepreneurial orientation and 33\% of them is related to the factors that are influential in entrepreneurial orientation, but are not mentioned in the model. Since the fitness indexes were higher than the required ones, it can be concluded that the conceptual model has a good fitness; it means that the collected data show the relations of the conceptual model. In this model, not all factor loadings are meaningful. Factor loadings that are shown in red demonstrated in Fig. 4 (individualism, the society's values, economic and political factors) are not meaningful. In other words, they do not have any significance effect on entrepreneurial orientation.

The other factor loadings shown in black color are meaningful in confidence level of 99 percent. Out of independent variables, just the variable of organizational factors (factor loading 0.95) had a significance effect on entrepreneurial orientation and as a general, independent variable $\left(\mathrm{R}^{2}=0.84\right)$ shows $84 \%$ of changes on independent variable of entrepreneurial orientation and the other $16 \%$ percent of them are the factors that are influential on entrepreneurial orientation, but were not mentioned in the model.

In $1^{\text {st }}$ conceptual model, organizational factors have a significance effect (factor loading 0.79 ) on entrepreneurial orientation. This factor loading has increased to 0.95 in $2^{\text {nd }}$ model. Encompassing the modifying variables in the model changes the effects of independent variable on dependent variable into an insignificance one. Thus, we can say that the effect of modifying variables is complete. Whereas, by encompassing the modifying variables into the model, the effect of independent variable on dependent one (factor loading) increases; thus, it can be mentioned that the effects of modifying variables is partial and positive. By comparing these two models, it can be concluded that the factor loading of independent variable increases by encompassing the modifying variables, which is significance; therefore, modifying variables have a significance effect on the relation between organizational factors and entrepreneurial orientation.

\section{Discussion and Conclusion}

In this research, the following tests were used to analysis the questionnaire's data: Factor analysis, the process in which the researcher has followed for testing the data, whether qualitative or quantitative, are as follow:

\subsection{Demographic data}

Reviewing the demographic data shows that more than half of the respondents had more than 20 years experiences, which shows high experience of bank employees. Moreover, $86 \%$ of the respondents were male and $14 \%$ of them were female. It shows the dominance of men in management positions in banks. Descriptive data also shows that $76 \%$ of the respondent had academic education, which shows the competences and abilities where they acquired form universities. In addition, it is observed that $46 \%$ of them were higher than 51 years old while just $8 \%$ of them were less than 30 years old.

\subsection{The findings of model analysis and testing the hypotheses}

Reviewing the results of testing the normal distribution of organizational, environmental and entrepreneurial orientation variables by use of One-Sample Kolmogorov-Smirnov Test showed that all of them had a significance coefficient higher than 5\%, thus, null hypothesis (H0) which suggests that the mentioned variable has a normal distribution is supported and we can conclude that the variable had normal distribution. The result of Pearson correlation coefficient shows that Cronbach's Alpha for the variables were more than 0.7 and it shows the reliability of the questionnaire. Moreover, the results of fitness test shows that the conceptual model has been an appropriate one.

The results of verifying factor analysis of different variables (RMSEA=0.000, P-value=1.0000) shows the fitness of the proposed model. It means that all of dimensions, components and variables 
defined for organizational factors and entrepreneurial orientation are appropriate and theoretically can determine the mentioned variables. Therefore, all of factor loadings of organizational factors and entrepreneurial orientation are significance all confidence level of 99 percent. With reference to $\left(R^{2}\right)$ and standardized coefficient, it can be mentioned that regarding organizational factors; senior management variable has the highest importance in determining the organizational factors and has the highest factor loading (0.63). Organizational system (0.58) and inter-organizational dynamism (0.45) are important respectively. In the case of entrepreneurial orientation; initiative variable has the highest importance in determining the entrepreneurial orientation and has the highest factor loading (0.90). Innovation (0.87) and risk (0.61) are the other important variables respectively.

The following results were determined regarding the hypotheses of this research:

The $1^{\text {st }}$ main hypothesis: organizational factors influence the entrepreneurial orientation in banking system of Iran.

Before analyzing this hypothesis and evaluating the results of different tests, the findings of Zahra and Dess (1991) were scrutinized, where organizational factors had the most importance effect on entrepreneurial orientation in different organizations in which different factors such as organizational controlling systems, organizational culture, organizational structure, and management support are some of organizational factors. Kuratko (1991) evaluated five different organizational factors of entrepreneurial orientation including senior management support, availability of resources and giving rewards, organizational support, risk and time. He concluded that senior management support, organizational structure and availability of the resources had the highest effect on development of entrepreneurial in various organizations. Holt (2007) also examined the role of organizational factors on entrepreneurial orientation in which some of the most important ones were sound rewarding system, risk and ignoring the job mistakes, management support, resources availability and supportive organizational structure. In this research, senior management support, dynamism between organization's units and organizational system were considered as some of the most effective organizational factors of entrepreneurial orientation.

In order to evaluate the effects of organizational factors on entrepreneurial orientation, the above mentioned hypothesis was analyzed. Regarding the level of significance level 0.000 (less than 0.05), $\mathrm{H}_{0}$ is rejected. Therefore, it can be mentioned that there is a significance difference between the mean of organizational factors and the tested value (3). Since upper and lower limits are positive, we can say that the mean of organizational factors' mean are higher than median and there are some suitable organizational factors for reinforcing the entrepreneurial orientation in private banks of Iran. Out of organizational factors, shaping constituent relations among organizational units, senior management support, lack of concentration and formality are more important than the other variables, but factors such as organizational conflicts and rewarding system are disrupting factors in which confirms that there are such conflicts in banking system of Iran.

Second hypothesis: environmental factors modify the extent of organizational factors influences on entrepreneurial orientation of banking system.

Before final analysis of this hypothesis and the results, which are extracted from various tests, it is necessary to review the literature. In this research, cultural, economic and political factors as well as the values of the society are considered as environmental factors where they can modify the extent of organizational factors influencing on entrepreneurial orientation. In order to examine the effects of these factors, some other four sub-hypotheses were formulated as follow:

$1^{\text {st }}$ sub-hypothesis: cultural factors significantly modify the relationship between organizational factors and entrepreneurial orientation.

In this research, the components of national culture including power gap, low uncertainty avoidance and individualism were considered as cultural variables of avoidance of low uncertainty. As the significance level is 0.000 (less than 0.05 ), $\mathrm{H}_{0}$ is rejected. Therefore, there is a significance difference 
between the mean of cultural variables and tested value (3). As the upper and the lower limit are positive, the mean of cultural factors' variable is more than median and cultural factors as modifying variable can reinforce the effects of organizational factors on avoidance of low uncertainty. Hence, the above mentioned features are low in banks which can elaborate entrepreneurial orientation in the banks. Therefore, the bank managers are capable of dealing with complex and dynamic environments and as a result have a higher orientation toward risk, competition in competitive environment and being different in supplying the higher quality and more appropriate price. All of these conditions demand some changes through innovation and using new techniques.

$2^{\text {nd }}$ sub-hypothesis: Economic factors significantly modify the relation between organizational factors and entrepreneurial orientation of banking system.

Reviewing the literature showed that economic conditions are the pre-requisite for emergence of entrepreneurial orientation culture. In this research, the purpose is to determine whether the economic conditions can be considered as an amplifying factor for reinforcing the entrepreneurial orientation or whether it is considered as a diminishing factor. The result showed significance level of 0.000 (less than 0.05 ) which result in rejection of $\mathrm{H}_{0}$. Therefore, there is a significance difference between the mean of economic factors variables and the tested value (3). Since the upper and the lower limit are negative, the mean of economic factors variables are less than median and the economic conditions are not important for banking system. This means that there is no constancy in monetary and macro management system of Iran's banks and they are independent. Moreover, the business condition of Iran is not suitable at all.

$3^{\text {rd }}$ sub-hypothesis: political factors significantly modify the relation between organizational factors and entrepreneurial orientation.

For the growth of entrepreneurial development, a political system composes of stable regulation, economic politics and competitive and freedom of choice environment is required. Moreover, the actions of the government are effective on entrepreneurial orientation. More specifically the extent of entrepreneurship development is directly dependent on society's regulations and rewarding policies of the government. Lazar and Hardin (1994) argued that interference of governments in organizations' affairs will lead to decrease of entrepreneurial orientation. As a result, the focus on managers' attention will be on implementing the governments' policies and not the components of entrepreneurship. Similarly, some other activities such as cooperation, team working and so on will be directed toward consistency and constancy and not entrepreneurship.

The results of the research show that the significance level is 0.000 (less than 0.05 ), therefore $\mathrm{H}_{0}$ is rejected and it can be inferred that there is a significance difference between the mean of political factors and the tested value (3). Since the upper and the lower limits are negative, the mean of political variables is less than the median. Therefore, the political conditions of Iran are not suitable for banking system of the country. This means that the regulations and the laws are not stable and there are plenty of repressive regulations for doing economic activities. The policies of government are not market-based which makes the conditions less competitive.

$4^{\text {th }}$ sub-hypothesis: the values of society very significantly modify the relation between organizational factors and entrepreneurial orientation of banking system.

Culture, customs and the values of the society are as important as the bed of innovation and development of entrepreneurship. In Quran, God invite people not only to thinking, criticism, reflection and wisdom, innovation and mental dynamism and development of sciences and discovering the unknowns but also to entrepreneurship and efficiency. The holy prophet (Mohammad) also put some emphasis on working and entrepreneurship as well. He recommended people to learn a new business, being time-conscious, learning knowledge and new skills, assiduity and innovation. Imam Ali (peace be upon Him) also tried his best to remove the obstacles of 
development and innovation in the society. He also enumerates some of the other barriers of innovation and emphasis on removing them for the society. Regarding the significance level of 0.020 (less than 0.05), the $\mathrm{H}_{0}$ is rejected. Therefore, there is a significance difference between the mean of society's values' variables and the tested value (3). Since the upper and the lower limits are negative, therefore the mean of society's values are less than the median and there is not suitable conditions for development of entrepreneurial orientation in the society. This means that the conditions of the society is not suitable for suggesting and implementing new ideas and investment and performing new businesses are not considered as a value in the society. Subsequently, the values of the society, which are extracted from Holy Quran, the narratives of Holy Prophet and Imam Ali and are encouraging innovation, business and entrepreneurship are not implemented in the society.

$3^{\text {rd }}$ main hypothesis: entrepreneurial orientation has a good condition in banking system of Iran.

Lumpkin and Des (1996) considered entrepreneurial orientation consisting of processes, structures and behaviors which can be explained as innovation, imitativeness and risk. The innovation component explains some efforts toward thought, innovation and technologic leadership in products and processes. Moreover, imitativeness, independence and risk imply to the actions of people or teams, which have tendency to implement new ideas or businesses. Reviewing the researches shows that entrepreneurial orientation has a great importance in increasing the effectiveness of organizations in competitive environment. One of the purposes of this research project was to examine the conditions of entrepreneurial orientation in Iran's banks towards determining the tendency of them to innovation, imitativeness and risk. With reference to significance level of 0.000 (less than 0.05), it can be concluded that $\mathrm{H}_{0}$ is rejected. Therefore, there is a significance difference between the mean of entrepreneurial orientation and the tested value (3). Since the upper and the lower limits are positive, the mean of entrepreneurial orientation is greater than the median and the banks have a good condition in risk, innovation and imitativeness.

\section{Discussion and Conclusion}

As mentioned earlier, to design the conceptual model, some reliable models were considered in the first stage. In addition, the conditions of the country in economic, political and cultural components were regarded as modifying variables and with reference to the reviews which were done regarding the instruments and pre -test as well as the interview with the academic experts, the social values were added to the model due to their role in amplifying the entrepreneurial orientation. The variables of supreme management and "creating organizational unit" were omitted from the components of organizational systems of the model as well. In order to design a model for entrepreneurial orientation, LISREL software was used to determine the causal relations and the significance of the relations as a whole and to determine the path coefficient and the direct and indirect effects of each variable on its following one. Data analysis regarding each dimension, component and variable of the model shows that three main hypotheses and seven sub-hypotheses were supported by use of statistical tests in a way that there was a significance relationship among independent variables (organizational factors), modifying (environmental factors) and dependent variables (entrepreneurial orientation). As the fitness indexes are higher than normal ones, the conceptual model has a good fitness; it means that the collected data show the relations of the conceptual model very appropriately. All of the factor loadings were meaningful at the confidence level of 99 percent. This model can be considered as an aborigine model of entrepreneurial orientation for policymakers and senior managers of Iran's banking system. It can also be considered as a framework for amplifying the innovation, imitativeness and risk of banks toward facilitating the conditions of effective development of entrepreneurship in banking system of Iran.

\section{References}

Covin, J.G. (1991). Entrepreneurial versus Conservative Firm. Journal of Management Studies, 28, 39-51. 
Covin, J., \& Slevin, D. (1991). A Conceptual Model of Entrepreneurship as firm behavior. Entrepreneurship Theory and Practice, 16(1), 7-25.

Covin, J., \& Miles P. (1999). Corporate Entrepreneurship and Pursuit of Competitive Advantage. Entrepreneurship Theory and Practice, 23(3), 47-63.

Covin, J. G., Green, K. M., \& Slevin, D. P. (2006). Strategic Process Effects on the Entrepreneurship on the Entrepreneurial Orientation. Entrepreneurship: Theory and Practice, 30(1), 57-81.

Dess, G. D. (1999). Linking Corporate Entrepreneurship to Strategy. Structure \& Process, Entrepreneurship: Theory \& Practice, 23(3), 85-96.

Dess, G. G., \& Lumpkin, G. T. (2005). The role of entrepreneurial orientation in simulating effective corporate entrepreneurship. Academy of Management Executive, 19, 14-25.

Holt, T. (2007). Corporate Entrepreneurship. Journal of Organization Change Management, 21, 14-31.

Hisrich, R.D. \& Peters, M.P. (2005). Establishing a new business venture unit within a firm. Journal of Business Venturing, 1(3), 307-322.

Hill, M. E. (2003). The Development of an instrument to measure entrepreneurship: entrepreneurship within the corporate setting. Journal of Marketing, 57, 44-56.

Hornsby, J.S., Kuratko, D.F., Shepherd, D.A., \& Bott, J.P. (2009). Managers Corporate Entrepreneurship Actions. Journal of Business Venturing, 24, 236-247.

Hill, M.E. (2003). Entrepreneurship within the corporate setting. Journal of Business and Entrepreneurship, 21(1).

Hitt, M., Ireland, R., \& Sexton, D. (2001). Strategic Entrepreneurship. Strategic Management Journal, 22, 479-491.

Jaworski, B., \& Kohli, A. (1993). Market orientation: Antecedents and consequences. Journal of Marketing, 57, 53-70.

Jaworski, B.J., Kohli, A.K. and Sahay, A. (2000). Market Driven Versus Driving Markets. Journal of the Academy of Marketing Science, 28, 45-54.

Knight, G. (2009). Entrepreneurship and Strategy in the International SME. Journal of International Management, 7(3), 155-171.

Knight, G. (2000). Entrepreneurship and Marketing Strategy. Journal of International Marketing, 8, 12-32.

Kuratko D.F \& Hodgetts, R.M. (2001). Entrepreneurship: A contemporary approach. Harcourt, Inc.

Kuratko, D.F., \& Hodgetts, R.M. (2006). Entrepreneurship, Thomson Corporation.

Kuratko, D. F. (2007). The Entrepreneurial intensity of corporate entrepreneurship. Journal of Leadership, 35, 40-56.

Lee, S. M., \& Peterson, S. J. (2000). Culture, entrepreneurial orientation and global competitiveness. Journal of World Business, 35(4), 401-416.

Kuratko, D.F., \& Hodgetts, R.M. (2001). Entrepreneurship a Contemporary Approach. Harcourt College Publisher.

Lumpkin, G. T., \& Dess, G. (2006). Clarifying the Entrepreneurial Orientation Construct and Linking it to Performance. The Academy of Management Review, 21(1), 135-172.

Lumpkin, T. G., \& Dess, G. (2001). Linking two dimensions of entrepreneurial orientation to firm performance: the moderating role of environment. Journal of Business Venturing, 16, 429-431.

Lumpkin, G. T., \& Dess, G. (1996). Enriching the entrepreneurial orientation construct. The Academy of Management Review, 21, 605-607.

Morris, M. H. (1998). Entrepreneurial intensity, Westport, CT: Quorum Books.

Miles, M. P., \& Covin, J. (2002). Exploring the practice of corporate venturing. Entrepreneurship Theory and Practice, 26, 21-40.

Miller, D., \& Friesen, P. (1982). Innovation in conservative and entrepreneurial firms: Two models of strategic momentum. Strategic Management Journal, 3, 1-25.

Morris, H. M., \& Kuratko, J.G. (2002). Corporate Entrepreneurship. Thompson. South - Western.

Patrick, M., \& Davis, J. (2010). Entrepreneurship orientation and firm performance. Journal of Small Business and Entrepreneurship, 23(1), 39-51.

Zahra, S.A., \& Dess, G.(2001). Entrepreneurship as a field of research. Academy of Management Review, 26, 8-20. 